\title{
Initial NARCliM Evaluation
}

\author{
J.P. Evans ${ }^{a}$, L. Fita ${ }^{a}$, D. Argüeso ${ }^{a}$ and Y. Liu \\ ${ }^{a}$ Climate Change Research Centre and ARC Centre of Excellence for Climate System Science, University of \\ New South Wales, Sydney, Australia \\ Email:jason.evans@unsw.edu.au
}

\begin{abstract}
NARCliM (NSW/ACT Regional Climate Modelling project) is a regional climate modeling project for the Australian area. It will provide a comprehensive dynamically downscaled climate dataset for the CORDEX-AustralAsia region at $50 \mathrm{~km}$, and South-East Australia at a resolution of $10 \mathrm{~km}$. NARCliM data will be used by the NSW and ACT governments to design their climate change adaptation plans.

NARCliM uses WRFv3.3 regional climate model (RCM) to perform an ensemble of simulations for the present and the projected future climate. WRF is run in three different model configurations (different combinations of physical parametrizations) that have been shown to perform well in the South-East Australia and were chosen based on performance and independence. These three RCMs are simulating three different periods: 1990-2009, 2020-2040 and 2060-2080. Four different GCMs (MIROC-medres 3.2, ECHAM5, CGCM 3.1 and CSIRO mk3.0) from CMIP3 will be used as initial and boundary conditions for the WRF simulations. These GCMs were chosen through a process that considered model performance, independence and projected future changes. Thus an ENSEMBLE of 12 simulations for each period will be obtained. Additionally to the GCM-driven simulations, 3 control run simulations driven by the NCEP/NCAR reanalysis for the entire period of 1950-2009 are also performed in order to validate the RCMs performance in the area. In this talk, we will present the initial evaluation results of the long control period simulations of the project. This includes an analysis of the models ability to capture the influence of large scale oceanic modes on the regional climate.
\end{abstract}

Keywords: $\quad$ Regional climate, Australia, model, WRF 


\section{INTRODUCTION}

Future climate change has been recognised as one of the largest issues facing the world in the coming century. The Intergovernmental Panel on Climate Change (IPCC) has been tasked with compiling the state of knowledge in relation to climate change on a regular basis. To date they have produced four such assessments with the fifth due in 2013-2014. These assessments are the basis of knowledge used by most governments to establish climate change related policy including the ongoing debates around the introduction of a price on greenhouse gas pollution.

Global Climate Models (GCMs) are the main tools used to project the extent of this future climate change. The Coupled Model Intercomparison Project 3 (CMIP3, Meehl et al., 2007) was the international collaborative effort of GCM groups to produce projections that directly informed the IPCC fourth assessment report (IPCC, 2007). This database of global climate projections has been widely used to investigate global climate system processes (e.g. Diffenbaugh et al., 2008; de Szoeke and Xie, 2008) as well as large scale climate change projections (Marriotti et al., 2008; Evans, 2009a; Vavrus et al., 2009; Evans 2010). This construction of a many GCM ensemble is vital for dealing with the uncertainty associated with future projections. Every GCM, that performs adequately for the recent past, provides a plausible projection of future climate and it is difficult to know which of these plausible futures is more likely. Hence the use of a many model ensemble is required to provide some measure of likelihood of the projected future climate.

As the risks associated with large scale climate change have become better understood, more impact and adaptation studies have been performed. A significant spatial scale problem exists between the scale of the GCMs (200-400km) and the scales of interest for impacts and adaptation studies which are often only tens of kilometres or less. In order to address this spatial scale problem various methods to downscale the GCM output have been developed. These downscaling methods can be generalised into two types: statistical and dynamical. Statistical downscaling involves deriving statistical relationships between some large scale predictors and the local variable of interest. An example would be to use the GCM predicted mean sea level pressure or $500 \mathrm{hPa}$ geopotential height to predict precipitation at a station location. It is then assumed that this statistical relationship remains true in a future changed climate and hence can be used to downscale both the present and the future climate. Dynamical downscaling uses mathematical representations of the physical processes that create the climate system, similar to GCMs, applied at a higher spatial resolution than the GCMs. In this way they are able to capture climate phenomena not resolved by the GCMs including the influence of mountains and coastlines and local land-atmosphere feedbacks (Zaitchik et al., 2007a,b). Dynamical downscaling is done with a Regional Climate Model (RCM). When downscaling future climate projections RCMs assume that the physical laws remain the same. Statistical downscaling techniques can also be applied to RCM output in order to provide information at point locations.

One advantage of statistical techniques is that they are less computationally intensive and hence can be used to downscale many GCM (or RCM) climate projections. This allows the statistical techniques to be applied to many climate models and hence they can span the range of plausible future climates. RCMs on the other hand, are quite computationally intensive and to date this has prevented them from being used to downscale many GCMs, hence they have not sampled the full range of plausible future climates. This issue has been addressed in a number of large international projects focused on Europe (PRUDENCE - Christensen and Christensen (2007), ENSEMBLES - van der Linden and Mitchell (2009)) and North America (NARCAP Mearns et al. (2009)) that produced large ensembles of RCM simulations. PRUDENCE was the first attempt to produce a RCM ensemble through a large cooperative international program. In this case several RCMs were used to downscale the same GCM thus providing a measure of the uncertainty associated with RCM simulations but not placing this within the context of plausible future climates simulated by GCMs (Deque et al., 2005). Both ENSEMBLES in Europe and NARCAP in North America, have attempted to address this issue by using a collection of RCMs to downscale a collection of GCMs. While these projects have found significant spread amongst the RCMs it has generally been smaller than the spread found in the full GCM ensemble (Fowler et al., 2007). Thus, an emphasis on sampling the GCM ensemble more comprehensively has been recommended (Kendon et al., 2010). 


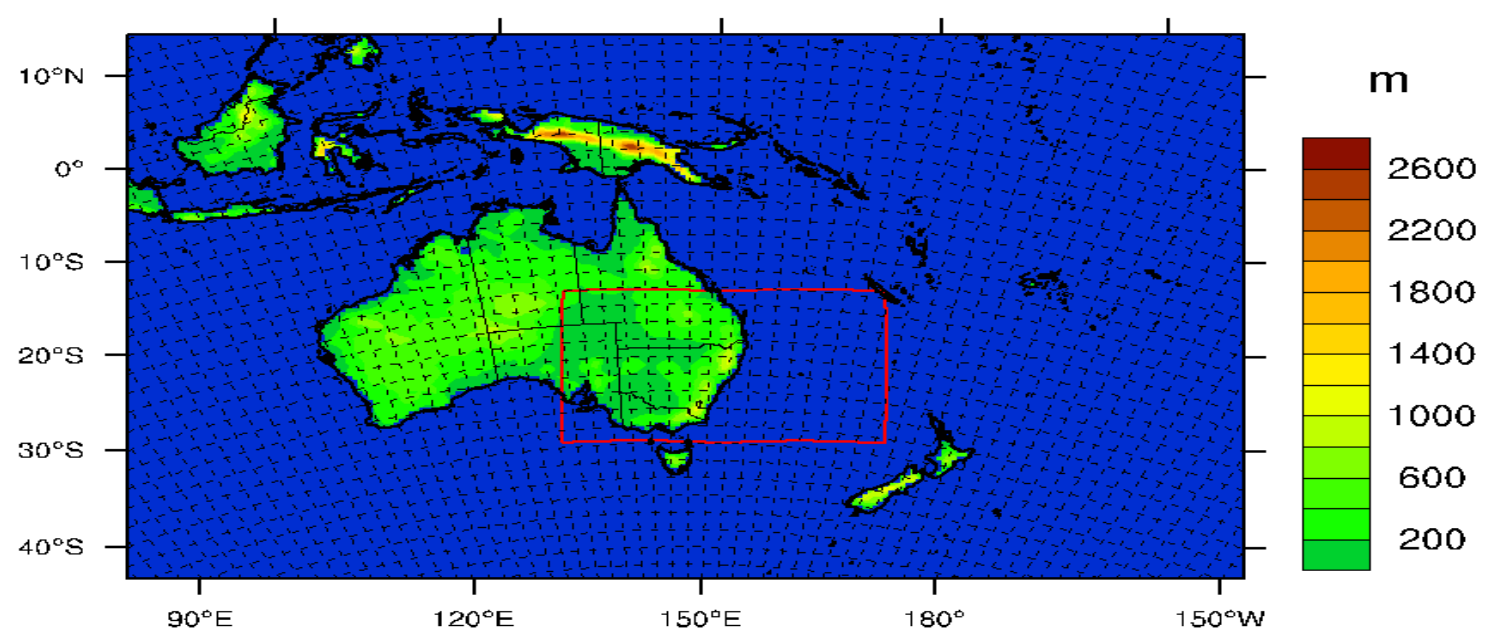

Figure 1. AustralAsia domain and topography. The red rectangle outlines the high resolution south-east Australia NARCliM domain.

The regional benchmark statistics will include both general comparisons of observed and modelled variables, as well as metrics aimed at particular phenomena such as the onset and evolution of the monsoon. Many studies have looked at various aspects of the climate system to evaluate RCMs, often with a focus on temperature and precipitation as these are the best observed climate variables. For example, Evans et al. (2005) investigated the performance through time of many variables but only for a single grid point. Kostopoulou et al. (2009) looked at maximum and minimum temperature on a seasonal basis. Evans (2009) and Evans et al. (2004) used temperature and precipitation on climatological and monthly time scales. Salon et al. (2008) focused on precipitation at the monthly to annual time scale. Rummukainen et al. (2001) evaluated seasonal to annual temperature and precipitation as well as sea surface temperatures of the Baltic Sea. Solman et al. (2008) looked at seasonal means and cycles, inter-annual variability and extreme events in precipitation and surface air temperatures. While Evans and McCabe (2010) evaluated a RCM against precipitation and temperature at daily, monthly, inter-annual and multi-annual time scales including the representation of El Niño - Southern Oscillation (ENSO) and the impact of drought. In addition Argüeso et al. (2012) evaluated the ability of an RCM to simulate both the mean and extreme precipitation over Spain.

When studying future regional climate changes, there are many different sources of uncertainty. Here these sources of uncertainty are broken down into three main sources, a different but similar way to categorise these sources of uncertainty can be found in Foley (2010). The first source, and one of the largest unknowns, is the future emissions of greenhouse gases. Since this is dependent on human activities and policy actions, the future evolution of greenhouse gas emissions is presented as a series of possible emission scenarios or projections. These scenarios are then used in GCM simulations to study the impact on climate. The GCM model physics and numerical structure are the second source of uncertainty. The last main source of uncertainty is the downscaling method itself. In the case of RCMs this includes the model physics and structure similar to issues associated with GCMs, while for statistical downscaling this includes uncertainties associated with the statistical technique used. In combination these sources of uncertainty provide a limit to the confidence that can be placed in any particular projection of future regional climate.

Quantifying this uncertainty is done by creating a collection, or ensemble, of climate simulations that sample various parts of the uncertainty described above. Emission scenario uncertainty is addressed by running simulations from more than one scenario. To quantify the uncertainty associated with GCMs an ensemble of many GCMs should be used and similarly for RCMs (or dynamical downscaling) many RCMs should also be used. Ideally these GCMs and RCMs would be independent of each other ensuring they are sampling from different parts of the plausible future climate space. Once an ensemble which samples these uncertainties has been established there are multiple methods for combining the information to establish a probabilistic future climate change prediction. Déqué and Somot (2010) used a technique that weights a frequency distribution based on model performance. Bayesian analysis has also been used in a number of ways (Tebaldi et al., 2004, 2005; Buser et al., 2010) and is an area of active research. 

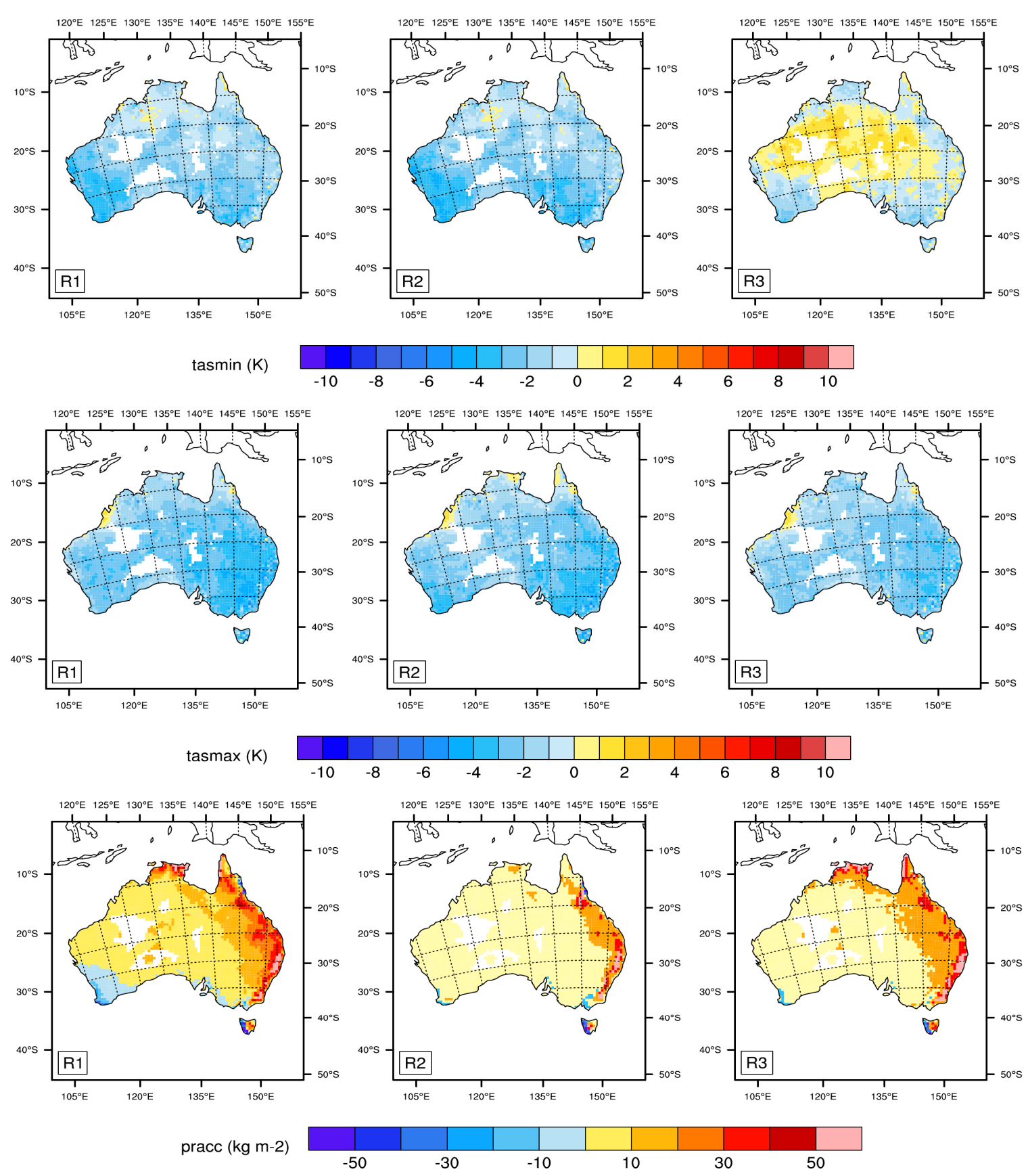

Figure 2. AWAP - Model for minimum temperature(tasmin), maximum temperature (tasmax) and precipitation (pracc) (rows) for each RCM (columns). White areas within Australia indicate areas of missing observational data.

\section{NARCLIM PROJECT PLAN}

The NARCliM ensemble has been designed to produce 12 regional climate model simulations. Twelve RCM runs (4 GCMS x 3 RCMS) were selected as a minimum number of runs to improve the probability of capturing the range of possible future climates. The process of developing the 12 RCMs first includes the selection of the GCMs that will be downscaled. The project will be run using four independent GCMs to provide the boundary conditions for three RCM simulations each, for a total of 12 runs. The GCM selection process was based on a combined evaluation of GCM performance in simulating actual climate for this region, provide independent estimates of the future climate and that provide an ability to span the range of 

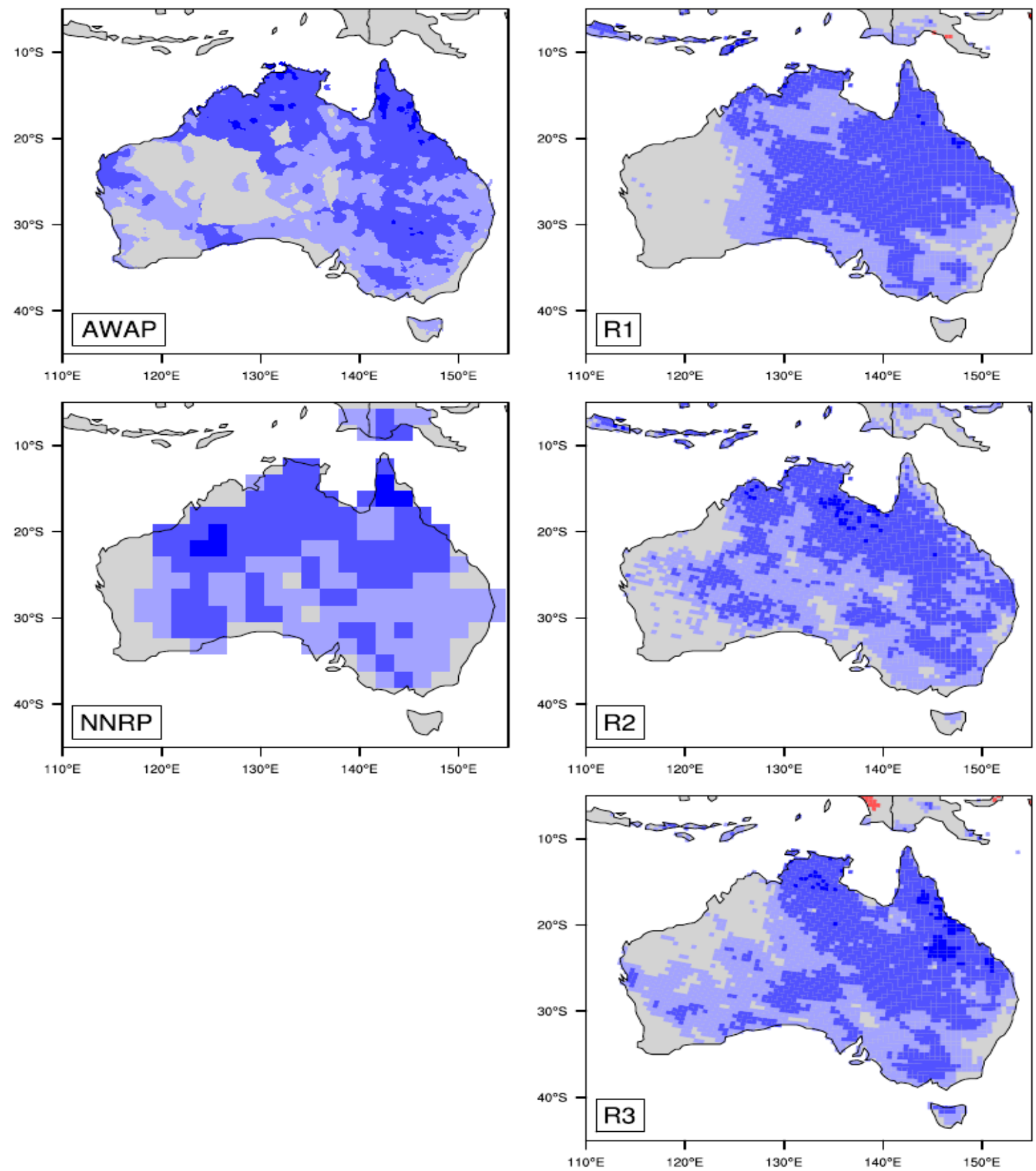

correlation

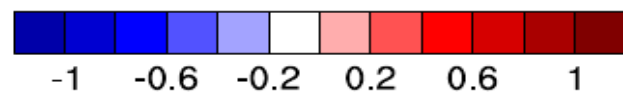

Figure 3. Correlation between SON precipitation and the El Niño Modoki Index. Only areas obtaining 95\% significance or higher are coloured.

future climate change projections. Three 20 year simulations will be performed with each of the 12 GCM/RCM combinations, for the present day (1990-2010) and two future periods, 2020-2040 and 20602080. In addition to the GCM driven simulations the RCMs will use boundary conditions from reanalysis to produce long (60-year) historical simulations. The NARCliM domain is shown in Figure 1. The large out domain is modelling using $\sim 50 \mathrm{~km}$ resolution while the inner high resolution domain is modelled using $\sim 10 \mathrm{~km}$ resolution. The resolution is chosen in order to capture important local land-atmopshere coupling feedbacks (Evans et al. 2011). The RCMs chosen are three different configurations of the Weather Research 
and Forecasting (WRF) model that has been shown to perform well over the region across a range of time scales (Evans et al. 2012; Evans and Westra, 2012; Evans and McCabe, 2013).

\section{RESULTS}

Here, some initial results from the reanalysis driven simulation are presented. Model results are compared to gridded observations of temperature and precipitation from the Bureau of Meteorology's Australian Water Availability Project (BAWAP - Jones et al. 2009). Figure 2 shows the bias in minimum and maximum temperature and precipitation as an example of the analysis performed. This demonstrates the independent nature of the model responses from each RCM with R1 and R2 underestimating minimum temperature but $\mathrm{R} 3$ often having a small overestimation; all three RCMs underestimating the maximum temperature; and R2 producing the best precipitation simulation with only small overestimates along the Great Dividing Range, while R1 \& R3 overestimate over eastern Australia and R1 underestimates over south-west W.A.

The RCMs have also been investigated for their ability to reproduce observed relationships between local climate variables and large scale oceanic modes. Figure 3 shows the correlation of SON precipitation for observation, reanalysis and the RCMs, with the El Niño Modoki Index obtained from JAMSTEC (http://www.jamstec.go.jp/frcgc/research/d1/iod/modoki home.html.en). Overall the RCMs all do a good job of capturing this correlation. In some locations, such as the south-east quarter of the continent, the RCMs are able to improve upon the driving reanalysis. Many relationships with other large scale modes (El Niño, Indian Ocean Dipole, Southern Antarctic Mode,...) have also been examined and have been found to be captured well.

\section{CONCLUSIONS}

This initial evaluation of NARCliM simulations shows that they do a good job at simulating the climate of Australia with a small cold bias and overestimation of precipitation on the Great Dividing Range. The differing responses of the different RCMs confirms the utility of considering model independence when choosing the RCMs. The RCM response to large scale modes of variability also reflect the observations well. At least in part this response is driven by the reanalysis, which is capturing phenomena occurring outside the RCM domain, however the RCMs are not bound entirely to the driving reanalysis and can vary the location and/or strength of the correlations found.

\section{ACKNOWLEDGEMENTS}

The NARCliM project is funded and managed by the NSW Office of Environment and Heritage. This research was undertaken with the assistance of resources provided at the NCI National Facility systems at the Australian National University through the National Computational Merit Allocation Scheme supported by the Australian Government.

\section{REFERENCES}

Argüeso, D., J.M. Hidalgo-Muñoz, S.R. Gámiz-Fortis, M.J. Esteban-Parra, Y. Castro-Díez(2012), Evaluation of WRF Mean and Extreme Precipitation over Spain: Present Climate (1970-99), J. Climate. $254883-$ 4897.

Christensen, J., and O. Christensen (2007), A summary of the PRUDENCE model projections of changes in European climate by the end of this century, Climatic Change, 81, 7-30, doi:10.1007/s10584-006-9210-7.

de Szoeke, S., and S. Xie (2008), The tropical eastern Pacific seasonal cycle: Assessment of errors and mechanisms in IPCC AR4 coupled ocean - Atmosphere general circulation models, Journal of Climate, 21(11), 2573-2590, doi:10.1175/2007JCLI1975.1.

Deque, M. et al. (2005), Global high resolution versus Limited Area Model climate change projections over Europe: quantifying confidence level from PRUDENCE results, Climate Dynamics, 25(6), 653-670, doi:10.1007/s00382-005-0052-1.

Deque, M., and S. Somot (2010), Weighted frequency distributions express modelling uncertainties in the ENSEMBLES regional climate experiments, Climate Research, 44(2-3), 195-209, doi:10.3354/cr00866.

Diffenbaugh, N., F. Giorgi, and J. Pal (2008), Climate change hotspots in the United States, Geophysical Research Letters, 35(16), doi:10.1029/2008GL035075.

Evans, J.P. (2009), Global warming impact on the dominant precipitation processes in the Middle East, Theoretical and Applied Climatology, 99(3), 389-402.

Evans, J.P. (2009a), 21 st century climate change in the Middle East, Climatic Change, 92(3-4), 417-432.

Evans, J.P. (2010) Global warming impact on the dominant precipitation processes in the Middle East. Theoretical and Applied Climatology, 99 (3-4), 389-402. 
Evans, J.P, M. Ekström, and F. Ji (2012) Evaluating the performance of a WRF physics ensemble over South-East Australia. Climate Dynamics, 39(6), 1241-1258, DOI 10.1007/s00382-011-1244-5.

Evans, J.P., and M. F. McCabe (2010), Regional climate simulation over Australia's Murray-Darling basin: A multitemporal assessment, J. Geophys. Res., 115(D14114), doi:10.1029/2010JD013816.

Evans, J.P. and M.F. McCabe (2013) Model resolution impact on regional climate and climate change using WRF over south-east Australia. Climate Research, 56(2), 131-145, doi:10.3354/cr01151.

Evans, J.P., R.J. Oglesby and W.M. Lapenta (2005), Time series analysis of regional climate model performance, Journal of Geophysical Research D: Atmospheres, 110(4), 1-23.

Evans, J.P., A.J. Pitman and F.T. Cruz (2011) Coupled atmospheric and land surface dynamics over South East Australia: A review, analysis and identification of future research priorities. International Journal of Climatology, 31, 1758-1772.

Evans, J.P., R.B. Smith and R.J. Oglesby (2004), Middle East climate simulation and dominant precipitation processes, International Journal of Climatology, 24(13), 1671-1694.

Evans, J.P. and S. Westra (2012) Investigating the Mechanisms of Diurnal Rainfall Variability Using a Regional Climate Model, Journal of Climate, 25, 7232-7247, doi:10.1175/JCLI-D-11-00616.1.

Foley, A. (2010), Uncertainty in regional climate modelling: A review, Progress in Physical Geography, 34(5), 647-670, doi:10.1177/0309133310375654.

Fowler H.J., S. Blenkinsop, C. Tebaldi (2007) Linking climate change modelling to impacts studies: Recent advances in downscaling techniques for hydrological modelling. International Journal of Climatology $27: 1547-1578$.

IPCC (2007), Climate Change 2007: The Physical Science Basis, edited by S. Solomon, D. Qin, M. Manning, Z. Chen, M. Marquis, K.B. Averyt, M. Tignor, H.L. Miller, Cambridge University Press, Cambridge, United Kingdom.

Jones, D. A., W. Wang, and R. Fawcett (2009) High-quality spatial climate data-sets for Australia. Australian Meteorological Magazine, 58, 233-248.

Kendon, E., R. Jones, E. Kjellstrom, and J. Murphy (2010), Using and Designing GCM-RCM Ensemble Regional Climate Projections, Journal of Climate, 23(24), 6485-6503, doi:10.1175/2010JCLI3502.1.

Kostopoulou, E., K. Tolika, I. Tegoulias, C. Giannakopoulos, S. Somot, C. Anagnostopoulou, and P. Maheras (2009), Evaluation of a regional climate model using in situ temperature observations over the Balkan Peninsula, Tellus, Series A: Dynamic Meteorology and Oceanography, 61(3), 357-370.

Mariotti, A., N. Zeng, J. Yoon, V. Artale, A. Navarra, P. Alpert, and L. Li (2008), Mediterranean water cycle changes: transition to drier 21st century conditions in observations and CMIP3 simulations, Environmental Research Letters, 3(4), doi:10.1088/1748-9326/3/4/044001.

Mearns, L. O., W. J. Gutowski, R. Jones, L.-Y. Leung, S. McGinnis, A. M. B. Nunes, and Y. Qian (2009), A regional climate change assessment program for North America, EOS, 90(36), 311-312.

Meehl, G. A., C. Covey, T. Delworth, M. Latif, B. McAvaney, J. F. B. Mitchell, R. J. Stouffer, and K. E. Taylor (2007), The WCRP CMIP3 multimodel dataset - A new era in climate change research, Bull. Amer. Meteor. Soc., 88(9), 1383-1394.

Rummukainen, M., J. Raisanen, B. Bringfelt, A. Ullerstig, A. Omstedt, U. Willen, U. Hansson, and C. Jones (2001), A regional climate model for northern Europe: model description and results from the downscaling of two GCM control simulations, Clim. Dyn., 17(5-6), 339-359.

Salon, S., G. Cossarini, S. Libralato, X. Gao, C. Solidoro, and F. Giorgi (2008), Downscaling experiment for the Venice lagoon. I. Validation of the present-day precipitation climatology, Climate Research, 38(1), 3141.

Tebaldi, C., L. Mearns, D. Nychka, and R. Smith (2004), Regional probabilities of precipitation change: A Bayesian analysis of multimodel simulations, Geophysical Research Letters, 31(24), doi:10.1029/2004GL021276.

Tebaldi, C., R. Smith, D. Nychka, and L. Mearns (2005), Quantifying uncertainty in projections of regional climate change: A Bayesian approach to the analysis of multimodel ensembles, Journal of Climate, 18(10), 1524-1540.

van der Linden, P., and J. Mitchell (Eds.) (2009), ENSEMBLES: Climate change and its impacts. Summary of research and results from the ENSEMBLES project, Met Office Hadley Centre, Exeter, UK.

Vavrus, S., D. Waliser, A. Schweiger, and J. Francis (2009), Simulations of 20th and 21st century Arctic cloud amount in the global climate models assessed in the IPCC AR4, Climate Dynamics, 33(7-8), 10991115, doi:10.1007/s00382-008-0475-6.

Zaitchik, B.F., J.P. Evans and R.B. Smith (2007a) Regional impact of an elevated heat source: The Zagros plateau of Iran. Journal of Climate, 20: 4133-4146.

Zaitchik, B.F., J.P. Evans, R.A. Geerken and R.B. Smith (2007b) Climate and vegetation in the Middle East: inter-annual variability and drought feedbacks. Journal of Climate, 20: 3924-3941. 